\title{
Variety, Vice, and Virtue: How Assortment Size Influences Option Choice
}

\author{
ANER SELA \\ JONAH BERGER \\ WENDY LIU*
}

\begin{abstract}
Assortment size has been shown to influence whether consumers make a choice, but could it also influence what they choose? Five studies demonstrate that because choosing from larger assortments is often more difficult, it leads people to select options that are easier to justify. Virtues and utilitarian necessities are generally easier to justify than indulgences; consequently, choosing from larger assortments often shifts choice from vices to virtues and from hedonic to utilitarian options. These effects reverse, however, when situational factors provide accessible reasons to indulge, underscoring the role of justification. Implications for choice difficulty and justification processes are discussed.
\end{abstract}

$\mathrm{W}$ hen going out to eat, consumers often get mired in one of life's eternal struggles - the choice between vice and virtue. Restaurant menus frequently include delicious but unhealthy options (e.g., pizza) as well as wholesome but less tasty alternatives (e.g., salads). Though such decisions can be resolved in different ways, one interesting question is whether menu size could influence what people choose. That is, could the number of options on the menu influence the type of option consumers select? For example, could longer menus lead people to choose more salads?

In recent years, a resurgence of interest in how variety influences consumer choice likelihood and satisfaction has offered an important correction to the notion that more choice is always better (Chernev 2003a, 2003b; Iyengar and Lepper 2000; Schwartz 2004). This stream of research demonstrates that too many options can lead consumers to not choose at all and to feel less satisfaction and more regret about the options they choose. But while this work has

*Aner Sela is a doctoral candidate in marketing at the Graduate School of Business, Stanford University, 518 Memorial Way, Stanford, CA 94305 (sela_aner@gsb.stanford.edu). Jonah Berger is assistant professor of marketing at the Wharton School, University of Pennsylvania, 700 Jon M. Huntsman Hall, 3730 Walnut Street, Philadelphia, PA 19104 (jberger@ wharton.upenn.edu). Wendy Liu is assistant professor of marketing at the Anderson School of Management, University of California, Los Angeles, 110 Westwood Plaza, Los Angeles, CA 90095 (wendy.liu@anderson.ucla .edu). The first two authors contributed equally to this research. The authors wish to thank Itamar Simonson, Uzma Khan, the editor, associate editor, and reviewers for helpful comments that greatly strengthened the article.

John Deighton served as editor and Stephen Nowlis served as associate editor for this article.

Electronically published October 15, 2008 provided insight into how the number of available options affects whether consumers make a choice (and their accompanying feelings), much less attention has been paid to how variety might influence what consumers choose.

This article examines how assortment size influences the choice between vice and virtue or hedonic and utilitarian options. When choosing whether to watch a slapstick comedy versus an award-wining drama, eat an ice cream bar versus a granola bar, or read a world news magazine versus a celebrity magazine, the number of options consumers choose from can vary greatly. They may choose TV shows from hundreds of cable channels or from only the basic networks, select food from a tiny hotel minibar or from a large vending machine, and pick a magazine from the few options available at the dentists' office or from the dozens available at the nearby Barnes and Noble. We argue that assortment size can have an important influence on option choice. Specifically, we integrate two research streamsassortment size and justification-to suggest that because choosing from larger sets is often more difficult, it will lead people to select more justifiable options. Further, because certain types of options are typically easier to justify (e.g., Kivetz and Simonson 2002b), increased variety should typically increase the choice share of such options. Five studies examine this possibility and test our underlying conceptual framework, exploring the hypothesized roles of choice difficulty and justification in these effects. We then discuss the theoretical and practical implications of our findings and develop directions for future research.

\section{VARIETY AND DECISION MAKING}

The number of available options can influence consumer choice in multiple ways. Decades of research suggest that 
choice increases satisfaction (e.g., Langer and Rodin 1976) and that larger assortments increase the likelihood that consumers will find an option that matches their preferences (Baumol and Ide 1956; Lancaster 1990). People actively seek variety (see Kahn and Ratner [2005] for a review), whether to satisfy the need for stimulation (Berlyne 1960) or for other reasons, and larger assortments help consumers satisfy these needs.

However, while much of the earlier work on variety either suggested or assumed that more options were better, recent research has highlighted the downsides of "too much choice." Choice can be overwhelming, and choosing from larger assortments increases choice difficulty and regret (Berger, Draganska, and Simonson 2007; Iyengar and Lepper 2000). Consequently, when faced with too many options, consumers may defer choice or not choose at all (Dhar 1997; Iyengar, Huberman, and Jiang 2004; Iyengar and Lepper 2000; Tversky and Shafir 1992). Consumers were less likely to purchase jam, for example, when they were given an extensive array of 30 flavors to choose from as opposed to a more limited array of six flavors (Iyengar and Lepper 2000). Similarly, choosing from larger assortments can influence consumers' postdecision satisfaction with their chosen options, leading to weaker preferences for the items selected and to greater regret (Chernev 2003b; Iyengar and Lepper 2000; Schwartz 2004).

Nevertheless, while the above research focuses on how variety influences choice difficulty, likelihood, and satisfaction, much less attention has been paid to how assortment size might influence the type of option consumers select. Although too many options may make choice difficult and lead consumers to defer choice or to not choose at all, what happens in the preponderance of situations in which consumers do make a choice? Could the number of alternatives influence the process by which people choose and, consequently, what they select?

\section{DECISION DIFFICULTY AND JUSTIFICATION}

When faced with difficult decisions, consumers often search for reasons to justify their choices. While normative theories focus on the utility associated with various aspects of the decision, other research notes that decision making is often driven by a reason-based analysis (Shafir, Simonson, and Tversky 1993). This framework suggests that consumers seek reasons to resolve conflict and justify the options they select. In such instances, consumers often focus their decision processes on the choice of good reasons rather than on the choice of good options (Simonson and Nowlis 2000). As the conflict and uncertainty associated with choice increases, the focus of consumers' reasoning processes may shift from desirability to justifiability. Options that provide convincing, readily justifiable arguments are therefore more likely to be chosen (Shafir et al. 1993; Simonson 1989, 1992).

Certain types of options are easier to justify than others.
Broadly speaking, it is easier to justify the choice of utilitarian necessities and virtues as opposed to hedonic indulgences and vices (Bazerman, Tenbrunsel, and Wade-Benzoni 1998; Kivetz 1999; Kivetz and Keinan 2006; Kivetz and Simonson 2002a). Hedonic consumption is harder to justify, in part, because it is often associated with guilt (Kivetz and Simonson 2002b; O'Curry and Strahilevitz 2001; Prelec and Loewenstein 1998; Strahilevitz and Myers 1998). The Protestant ethic emphasizes frugality (Weber 1958), and consumers sometimes feel guilty about pleasurable consumption (Lascu 1991). In addition, it is often easier to construct reasons to justify utilitarian consumption. The benefit of hedonic goods lies in experiential enjoyment, which is harder to quantify than the more concrete benefits that utilitarian goods often provide. Quantifiable reasons are more easily justified (Hsee 1995; Shafir et al. 1993), and the search for reasons may increase utilitarian choice.

Consequently, situations that increase reliance on available justifications can affect the types of options consumers select. For example, choosing for public rather than private consumption generally favors options that are higher on utilitarian aspects (Böhm and Pfister 1996). People were less likely to prefer an elegant motor scooter as a prize over more virtuous options when they would supposedly receive it on a public TV show as opposed to in a private mail lottery. Importantly, however, the same mechanism can potentially make people more likely to prefer hedonic options if situational factors provide accessible reasons to indulge. For example, a task involving much personal effort might lead people to select a hedonic reward because they feel they have "earned" the right to indulge and thus can justify such a choice (Kivetz and Simonson 2002a; Kivetz and Zheng 2006).

\section{THE CURRENT RESEARCH}

Building on these findings, we argue that assortment size will influence the type of options consumers select. Further, we develop a justification-based framework to account for these effects. Because choosing from larger assortments tends to be more difficult, we argue that it will often lead consumers to select options that are easier to justify, such as healthy food or highbrow television. Consequently, people faced with a larger menu might be more likely to take the garden salad over the pepperoni pizza or the reduced fat strawberry ice cream over the double chocolate mocha crunch. Similarly, choosing from a larger array of channels might lead people to choose award-winning dramas and insightful news over slapstick comedies and shoot-'em-up action movies.

However, while healthier or more virtuous options tend to be easier to justify in general, situational factors can provide accessible justifications to indulge. Consequently, we propose that the effect of variety on choice will be moderated by accessible justifications. Under neutral or lowjustifiability conditions, choosing from larger assortments will increase the share of utilitarian or virtuous options. However, when situational factors provide accessible rea- 
sons to indulge, choosing from larger assortments will have the opposite effect, increasing the share of vices or hedonic choices.

Five studies test these hypotheses. First, they examine whether assortment size can influence the type of options consumers select. They demonstrate that choosing from a larger assortment can lead people to select reduced fat over regular ice cream (experiment 1A), fruit over cookies (experiment $1 \mathrm{~B}$ ), and utilitarian over hedonic consumer products (experiments 2-5). Second, the studies test the underlying mechanism behind these effects. They examine the mediating role of choice difficulty (experiment 3 ) and the moderating role of accessible justifications (experiments 4 and 5).

\section{EXPERIMENT 1: VARIETY AND OPTION CHOICE}

\section{Experiment 1A: Ice Cream}

Experiment $1 \mathrm{~A}$ provides a preliminary investigation into whether assortment size influences the type of options consumers select. Participants were shown either a smaller or a larger array of ice cream options and were asked to choose the option they liked best. Each flavor had both a regular version and a reduced fat version. We compared the likelihood of selecting a regular versus a reduced fat option across the two conditions. Prior research suggests it is often harder to justify indulgences (Kivetz and Simonson 2002b). Thus, we predict that people choosing from a larger assortment will be more likely to select reduced fat ice cream.

\section{Method}

Participants. One hundred and twenty-one respondents completed a group of studies in exchange for a chance to win a $\$ 25$ gift certificate.

Materials and Procedure. Participants were shown pictures of ice cream and were asked to select their preferred flavor. For each flavor there was both a regular version (e.g., vanilla) and a reduced fat version (e.g., reduced fat vanilla). Both versions used the same picture but had different labels. The key difference between conditions was the number of available options. In the low-variety condition there were two options available, one regular and one reduced fat. In the high-variety condition there were 10 options available, five in each category.

\section{Results}

As predicted, assortment size influenced the type of option people chose. Participants who chose from a larger assortment were more likely to select a reduced fat flavor $\left(\chi^{2}(1)=4.08, p<.05\right)$. While only $20 \%$ of participants who chose from the smaller assortment selected reduced fat ice cream, $37 \%$ who chose from the larger assortment selected reduced fat.

\section{Experiment 1B: Fruit or Cookies?}

Experiment 1B used a real choice situation to investigate how assortment size influences option choice in a field setting. A tray containing fruits and cookies was placed at each of two building entrances, and a sign indicated that passersby could help themselves to an item. We manipulated whether the tray contained a smaller or a larger array of options. Consistent with our conceptualization, we predicted that people choosing from larger assortments would be more likely to select fruit over cookies.

\section{Method}

Participants and Procedure. Seventy-five people at Stanford University completed the study over the course of a day. Trays were mounted on stands and placed at two doors located on opposite sides of a campus building. Attached to each tray was a printed sign indicating, "Please help yourself to one item!" One tray contained six types of fruit (banana, red apple, pear, green apple, tangerine, and peach) and six types of cookies and cakes (chocolate chip, oatmeal raisin, white chocolate chip, and M\&M cookies; minicroissants; and banana nut muffins). The other tray contained only two options from each category. The exact content of the smaller assortment was constantly counterbalanced as options from the tray were consumed. The trays were swapped between locations once during the study. An experimenter refilled the trays as the food was selected and inconspicuously noted the options consumed from each tray. Our key dependent variable was the type of option (fruit or cookie) chosen.

\section{Results}

As predicted, participants were more likely to select healthy fruit over tempting cookies when choosing from a larger assortment $\left(\chi^{2}(1)=3.90, p<.05\right)$. While $55 \%$ of participants chose fruit over cookies from the smaller assortment, $76 \%$ of participants who chose from a larger assortment selected fruit.

\section{Discussion}

Experiments $1 \mathrm{~A}$ and $1 \mathrm{~B}$ provide preliminary support for our theorizing. Choosing from a larger set led consumers to select options that should have been easier to justify. People were more likely to select reduced fat over regular ice cream (experiment 1A) or fruit over cookies for a real lunchtime snack (experiment 1B) when they were faced with a larger array of options.

One might question, however, whether our results are due to the extra options available in the larger assortment conditions. Increasing the available options in a category should lead consumers to be more likely to find an option that fits their preferences. Participants in experiment $1 \mathrm{~A}$, for example, might have preferred reduced fat ice cream overall but chose regular ice cream in the smaller variety condition 
because, within the vanilla flavor, they happened to like regular more than reduced fat. Alternatively, one could argue that because each choice involves a trade-off between two salient goals (e.g., pleasure and good health), people balanced those goals within option choice (cf. Dhar and Simonson 1999). Participants might have settled for a less tasty ice cream (i.e., reduced fat) when variety ensured that they could get a preferred flavor but might have selected the tastier option (i.e., regular fat) from the smaller assortment when they could not get the flavor they preferred.

Experiment 1B partially addressed this issue by varying the specific content of the tray in the smaller variety condition throughout the experiment. To more directly rule it out, however, the next study examines whether increasing the number of either hedonic or utilitarian options increases the choice share of utilitarian items.

\section{EXPERIMENT 2: VARYING HEDONIC AND UTILITARIAN SET SIZE SEPARATELY}

Experiment 2 tests whether the effect of assortment size can occur independently of whether there is an increased number of hedonic or utilitarian options. Participants saw a set consisting of printers (smaller or larger variety) and MP3 players (smaller or larger variety) and were asked to indicate which of the available options they preferred. This allowed us to examine how both the overall assortment size and the relative number of options in each category affect the type of options consumers select.

We used these particular options because a pretest indicated that printers were perceived as more utilitarian, whereas MP3 players were perceived as more pleasurable. Specifically, pretest participants rated the extent to which each of these products provides practical benefits and pleasure. The results indicated that printers were perceived as providing more practical benefits than pleasure $\left(M_{\text {Prac. }}=\right.$ 5.45 vs. $\left.M_{\text {Pleas. }}=3.20 ; F(1,206)=287.02, p<.001\right)$, whereas the opposite was true for MP3 players $\left(M_{\text {Pract. }}=\right.$ 4.06 vs. $\left.M_{\text {Pleas. }}=5.68 ; F(1,206)=287.02, p<.001\right)$. Printers were also rated as providing more practical benefits than MP3 players $\left(M_{\text {Print. }}=5.45\right.$ vs. $M_{\mathrm{MP} 3}=4.06$; $F(1,206)=76.71, p<.001)$, whereas MP3 players were rated as providing more pleasure than printers $\left(M_{\mathrm{MP} 3}=\right.$ 5.68 vs. $\left.M_{\text {Print. }}=3.20 ; F(1,206)=303.95, p<.001\right)$.

Because utilitarian choices (i.e., printers) are generally easier to justify (Kivetz and Simonson 2002b), we predicted that increasing the number of available options would lead people to be more likely to select a printer. Importantly, however, our theoretical framework entails that increasing the number of either MP3 players or printers may lead to increased selection of printers in this instance, even when the number of products in the opposite category remains small.

\section{Method}

Participants. One hundred and one students at the University of California, Los Angeles (UCLA), completed the study as part of a larger group of unrelated experiments. They were randomly assigned to a condition and received $\$ 20$ for their time.

Materials and Procedure. Participants were shown an array of printers and MP3 players and were asked which of the available options they preferred. Options were organized in a two-row table with the upper row stating the option number and category (e.g., "Option 1: printer") and the lower row containing the product name (e.g., "Epson Stylus C88 printer"). The options for each category appeared in a row, and category order was randomized across participants. Each category featured prominent brand names, and no information about specific product attributes was provided. Thus, importantly, the level of similarity between options was kept identical across the two categories. Pretesting also indicated that none of the options dominated others within its category.

The key difference between conditions was the number of available options in each category. All participants were shown both printers and MP3 players, but how many of each appeared (two or six) varied independently in a 2 (printer variety: smaller vs. larger) $\times 2$ (MP3 player variety: smaller vs. larger) between-subjects design. The key dependent variable was whether participants selected a printer or an MP3 player.

\section{Results}

As predicted, assortment size influenced the type of option selected (fig. 1). Focusing first on the symmetrical choice sets: whereas only $11 \%$ of participants chose a printer in the smallest assortment condition (two printers and two MP3

FIGURE 1

\section{INFLUENCE OF VARIETY ON OPTION CHOICE} (EXPERIMENT 2)

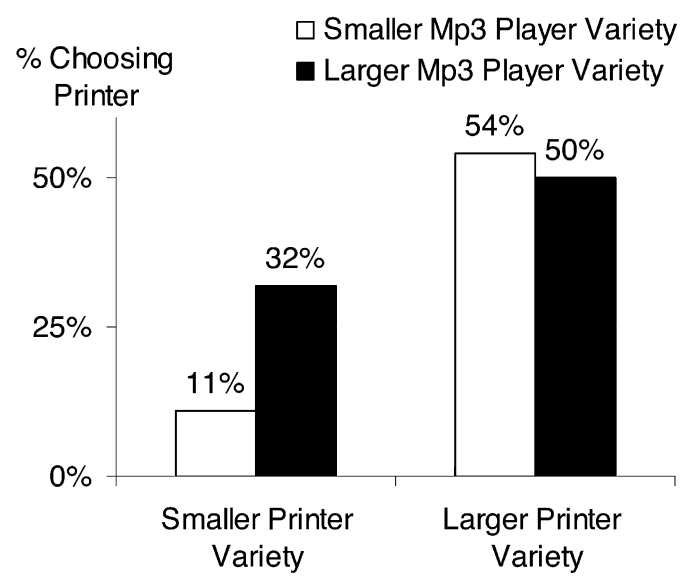


players), the percentage increased to $50 \%$ in the largest assortment condition (six printers and six MP3 players; $\left.\chi^{2}(1)=9.03, p<.005\right)$. Analysis of the asymmetric choice sets provides further insights. Compared with the smallest assortment condition, the number of people who chose a printer jumped to $32 \%$ when the number of MP3 players was increased $\left(\chi^{2}(1)=3.15, p<.08\right)$ and to $54 \%$ when the number of printers was increased $\left(\chi^{2}(1)=10.90, p<.001\right)$. This suggests that increasing the number of either printers or MP3 player options was sufficient to lead participants to choose more printers.

\section{Discussion}

Experiment 2 further supports our suggestion that assortment size can influence option choice. Larger assortments led consumers to select options that should have been easier to justify. Further, results from the asymmetrical choice sets cast doubt on the alternative account discussed previously. Even when the number of available printers remained constant, adding more MP3 players to the choice set increased the selection of printers. This underscores the notion that our findings are not driven by the particular options available in the larger set. This result also demonstrates another violation of the regularity condition (Shafir et al. 1993), whereby the tendency to select a particular option increases with the addition of alternatives.

The first two experiments consistently demonstrate that when faced with larger assortments, consumers tend to select options that are easier to justify. The next three experiments were designed to provide deeper insight into the mechanism underlying these effects. We theorize that increasing the number of options should increase the difficulty associated with choice, which, in turn, should drive people to select more justifiable options. We directly test this mediation hypothesis in experiment 3 .

\section{EXPERIMENT 3: THE MEDIATING ROLE OF CHOICE DIFFICULTY}

Experiment 3 examines the role of choice difficulty in the effect of assortment size on option choice. As in experiment 2, participants chose between different consumer electronics options (printers and MP3 players), from either a larger or a smaller choice set. After making their selections, participants rated the difficulty of the choice task. We predicted that difficulty would mediate the effect of assortment size on option choice. A larger choice set should increase choice difficulty, which, in turn, should lead consumers to select options that are easier to justify.

\section{Method}

Participants. One hundred and fifty-six respondents completed this experiment as part of a group of unrelated studies. They were randomly assigned to a condition and were given a chance to win a $\$ 25$ gift certificate in exchange for their participation.
Materials and Procedure. The study employed a similar paradigm as experiment 2 but with only two variety conditions: participants chose from either a smaller assortment (two printers and two MP3 players) or a larger assortment (six printers and six MP3 players). They were shown an array of printers and MP3 players and were asked which option they preferred. After making their choices, participants were asked to rate the extent to which they found it "difficult to make a decision about which option to pick" $(1=$ not at all difficult; $7=$ very difficult $)$.

\section{Results}

Effect of Assortment Size on Option Choice. Replicating the results of our prior experiments, assortment size influenced option choice; participants were more likely to choose a printer when choosing from a larger $(51 \%)$ as compared to smaller $(34 \%)$ set $\left(\chi^{2}(1)=6.27, p<.01\right)$.

Mediation Analysis. We also examined whether choice difficulty mediated the effect of assortment size on option choice (Baron and Kenny 1986). First, a logistic regression with option choice (printer vs. MP3 player) as the dependent variable and assortment size (smaller vs. larger) as the independent variable revalidated the effect of assortment size on choice $(\operatorname{Wald}(1)=6.18, p<.01)$. Next, a linear regression with choice difficulty as the dependent variable and assortment size as the independent variable indicated that increasing assortment size significantly increased choice difficulty $(B=.90, \mathrm{SE}=.30 ; t(154)=3.03, p<.005)$. Finally, a logistic regression model with choice as the dependent variable and assortment size and difficulty as the independent variables revealed a significant effect of difficulty on option choice $(B=.25, \mathrm{SE}=.09$; Wald $(1)=$ $7.15, p<.01)$, while the effect of assortment size on choice decreased $($ Wald $(1)=3.41, p<.07)$. A Sobel $(1982)$ test revealed that this decrease was significant $(z=2.01, p<$ $.05)$, indicating that the effect of assortment size on choice was mediated by choice difficulty.

\section{Discussion}

Experiment 3 again demonstrates that assortment size can influence option choice while also illuminating the process underlying these effects. Choosing from a larger assortment was more difficult, and this difficulty led people to select options that were easier to justify.

Consistent with research suggesting that utilitarian choices are generally easier to justify (Kivetz and Keinan 2006; Kivetz and Simonson 2002b), the first three studies have illustrated that larger assortments can lead consumers to select healthier food or more utilitarian consumer goods. But while such choices are typically easier to justify, specific situational factors (e.g., exerting effort or committing to virtuous choices) can provide justifications to indulge (Khan and Dhar 2006; Kivetz and Zheng 2006). Furthermore, the fact that accessible justifications can vary allows us to directly test our proposed mechanism. If ease of justification 
underlies the effect of assortment size on choice, as we suggest, then providing people with accessible justifications for hedonic choice should reverse the effect. We test this possibility in the final two studies.

\section{EXPERIMENT 4: MANIPULATING EASE OF JUSTIFICATION THROUGH PRIOR CHOICE}

If larger assortments lead people to resort to accessible justifications, as we suggest, then when justifications for indulging are made accessible, increased assortment size should lead people to choose more hedonic options. Prior research indicates that commitment to a virtuous act, such as volunteering, can activate a positive self-concept that subsequently licenses the choice of a self-indulgent option (Khan and Dhar 2006). We use such a licensing manipulation. Before the focal choice task, half our participants (high license condition) made a hypothetical choice between two volunteer activities. The other half (low license condition) made a hypothetical choice between two fun activities. All participants were then presented with either a smaller or a larger array of laptops and were asked to choose their preferred option.

We also used a framing manipulation to vary whether particular options were seen as hedonic or utilitarian without actually changing the options themselves. The laptops were grouped into two sets (A and B). For half the participants, options in one set were described as more fun oriented, while those in the other were described as more work oriented (see the appendix). For the other half, these labels were reversed. This manipulation bolsters construct validity because it allows us to vary option justifiability without confounding it with what is actually being chosen.

We hypothesized that the licensing manipulation would moderate the effect of assortment size on option choice. Specifically, the low licensing condition should replicate the results of our prior experiments. When faced with more options, participants should be more likely to choose utilitarian options (i.e., a laptop built for work). In the high licensing condition, however, assortment size should have the opposite effect. When faced with a larger set of options, these participants should be more likely to choose options that provide pleasure (i.e., a laptop built for fun). Further, the increased choice likelihood should depend on whether the laptops were framed as more hedonic or utilitarian, rather than on the actual options themselves.

\section{Method}

Participants. One hundred and seventy-one individuals participated in two ostensibly unrelated studies as part of a larger group of experiments. They were randomly assigned to conditions in a 2 (assortment size: smaller vs. larger) $x$ 2 (licensing: low vs. high) between-subjects design in exchange for the chance to win a $\$ 25$ gift certificate.

Licensing Task. Following Khan and Dhar (2006), we told participants that the first task was a survey about different decisions people face in everyday life. They were asked to imagine that they decided to dedicate 3 hours every week to a certain goal and then were asked to select a specific activity related to that goal. Participants in the high licensing condition were asked to imagine that they had volunteered to spend 3 hours a week doing community service. They were asked to choose between two activities, teaching children in a homeless shelter and improving the environment. In contrast, participants in the low licensing condition were asked to imagine that they had decided to spend 3 hours a week on fun activities. They were asked to choose between playing video games and watching television. All participants were also asked to state reasons for their respective choices, to ensure involvement in the task.

Choice Task. Participants then completed an ostensibly unrelated study in which they chose among different laptops. They were shown an array of laptops (e.g., Lenovo ThinkPad T60) and were asked to select the laptop they preferred. Laptops were grouped in two sets. Those in one set were described as "built for fun. They feature high-end graphics cards, top of the line speakers, and extra music and video software." Laptops in the other set were described as "built for work. They are lightweight, have extended battery life, high-end security, and extra business and presentation software." Importantly, these descriptions were counterbalanced across participants. For half the participants, laptops in set A were described as fun and laptops in set B as work oriented, and for the other half the descriptions were reversed. This design allowed us to examine whether the effects of assortment size on choice persist even when the options themselves remain the same.

In the smaller assortment condition, participants chose among four laptops (two fun oriented and two work oriented). In the larger assortment condition, they chose among 12 laptops (six of each). After selecting their preferred option, participants were probed for suspicion and were asked to indicate what they thought might have affected their decision in the choice task. None suspected that the licensing task was related to their subsequent choice.

\section{Results}

Analysis revealed that the effect of assortment size on option choice was moderated by accessible justifications (fig. 2). Results in the low licensing condition mirrored those of our prior experiments. Whereas only $30 \%$ of participants in the smaller assortment condition selected a work laptop, $52 \%$ chose a work laptop in the larger assortment condition $\left(\chi^{2}(1)=3.84, p<.05\right)$. In contrast, as predicted by our justification framework, the pattern in the high licensing condition was reversed. While $63 \%$ of participants in the smaller assortment condition chose a work laptop, this number was reduced to $39 \%$ in the larger assortment condition $\left(\chi^{2}(1)=5.11, p<.05\right)$. Labeling order did not have an effect on choice in either condition. 
FIGURE 2

\section{INFLUENCE OF VARIETY AND LICENSING ON OPTION CHOICE (EXPERIMENT 4)}

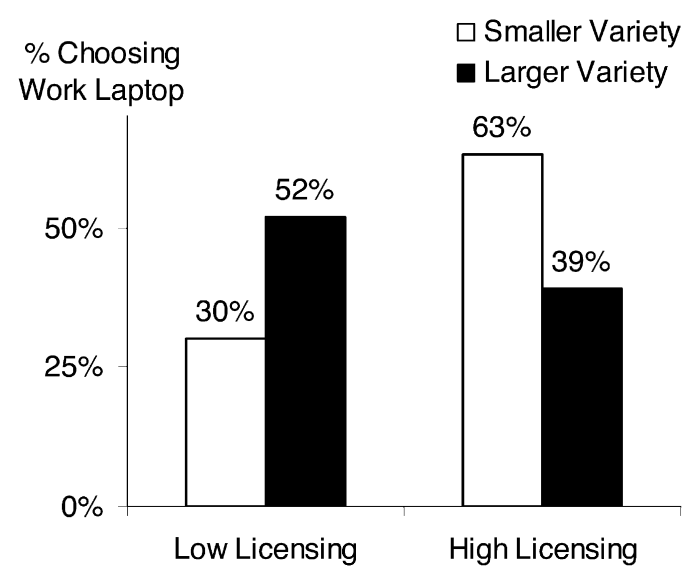

\section{Discussion}

The results of experiment 4 support our suggestion that accessible justifications moderate the effect of variety on option choice. Consistent with our previous studies, when pleasurable options were harder to justify (i.e., when a licensing manipulation suggested that participants did not earn the right to indulge), larger assortments led to increased selection of utilitarian options. In contrast, when participants had a readily accessible "excuse" for rewarding themselves (i.e., when the licensing manipulation suggested they had earned the right to indulge), greater assortment increased the likelihood of choosing pleasurable options. Further, by keeping the options themselves the same but manipulating the labeling, we underscore the hypothesized role of justification in these effects: increased assortment size led participants to choose options labeled in a way that made them easier to justify.

\section{EXPERIMENT 5: MANIPULATING EASE OF JUSTIFICATION THROUGH EFFORT}

Experiment 5 uses a different manipulation to provide convergent evidence for the role of justification in these effects. This allows us to capture two qualitatively different instantiations of justifiability, thus broadening the conceptual basis of our justification construct and ruling out additional rival accounts. We borrowed a relative-effort manipulation from prior work on justification that found that "expending high effort provides a compelling justification to indulge" (Kivetz and Zheng 2006, 574). Before our main assortment-size manipulation, participants were given an ostensibly unrelated survey that asked them to complete a set of simple problems. All participants completed the same number of problems, but those in the high relative-effort condition were led to believe that they completed more problems than other participants, thus providing them with an accessible "excuse" to reward themselves. Participants then completed the same choice task as in experiment 3 , in which they were asked to select an option from either a smaller or larger assortment of consumer electronics (i.e., printers and MP3 players).

We predicted that the low relative-effort condition would replicate the results of our other experiments; when faced with a larger set of options, participants will be more likely to choose utilitarian necessities (i.e., a printer). In contrast, participants in the high-effort condition should show the opposite effect. When faced with a larger set of options, these participants should choose options that provide pleasure (e.g., an MP3 player).

The design also allows us to test our justification-based explanation against an alternative account. One might suggest that, rather than justification, the effect of assortment size on choice was driven by the activation of different modes of thinking (Hsee and Rottenstreich 2004; Small, Loewenstein, and Slovic 2007). Having more options to choose from is associated with greater cognitive effort, which may put consumers in a cognitive mode of thinking. This, in turn, might benefit more cognitive (e.g., utilitarian) and less emotional (e.g., hedonic) options because such choices fit with the choice process being used. We tested this alternative account by modifying the relative-effort task used in prior work (Kivetz and Zheng 2006). Rather than complete sentences, participants solved math problems, which has been shown to activate a cognitive-based mode of thought (Hsee and Rottenstreich 2004). Participants solved the same number of problems in both high and low relative-effort conditions, and thus all participants should have had an equally cognitive mind-set activated. Further, a cognitive mode account would suggest that because variety induces greater cognitive trade-offs, it should always lead people to choose more utilitarian options, which are consistent with a more cognitive mode of thought. However, if greater assortment leads to choice of more hedonic options in the high relative-effort condition, as we predict, then it will contradict this account.

\section{Method}

Participants. One hundred and sixty-eight undergraduates at UCLA participated in two ostensibly unrelated studies as part of a larger group of experiments. They were randomly assigned to a condition and received $\$ 20$ for their time.

Relative-Effort Manipulation. The effort manipulation required participants to solve simple calculation problems-for example, "If an object travels at five feet per minute, how many feet will it travel in 360 seconds?" They were informed that the experimenters were interested in how different levels of effort influence people's performance on simple tasks. All participants were told that they would be randomly assigned to either a low- or a high-effort task. They were then given the same nine calculation problems, but we manipulated their perceived effort relative to other 
participants. In the low- (high-) effort condition, participants were told that "each participant is asked to solve anywhere between 8 to 16 [2 to 10] calculation problems. You have been assigned to the low [high] effort task." All participants then went on to solve the same nine problems. Thus, all participants expended the same amount of actual effort, but we varied the amount of effort participants felt they had exerted relative to other participants.

Procedure. First, participants completed the relativeeffort task. Then they moved on to a supposedly unrelated choice study. This task was printed using different font and layout than the effort manipulation task and consisted of the same choice task used in experiment 3. Participants chose from either a smaller set (two printers and two MP3 players) or a larger set (six printers and six MP3 players). After selecting their preferred option, they were probed for suspicion and were asked to indicate what they thought might have affected their decision in the choice task. None suspected that the effort task was related to their subsequent choice.

\section{Results}

As predicted, the analysis revealed that the effect of assortment size on option choice was moderated by perceived relative effort (fig. 3). Specifically, in the low relative-effort condition, the results mirrored the findings from the first three experiments. Whereas only $37 \%$ of participants in the smaller assortment condition selected a printer, this increased to $61 \%$ in the larger assortment condition $\left(\chi^{2}(1)=\right.$ $4.60, p<.05)$. In contrast, as predicted by our justification framework, the pattern in the high relative-effort condition was reversed. While $48 \%$ of participants in the smaller assortment condition selected a printer, the percentage dropped to $26 \%$ in the larger assortment condition $\left(\chi^{2}(1)=4.71\right.$, $p<.05)$. Participants who exerted high relative effort selected more hedonic options when choosing from a larger choice set. To look at the data another way, the relativeeffort manipulation influenced choice for participants faced with a larger assortment $\left(\chi^{2}(1)=10.74, p<.001\right)$ but not for participants faced with a smaller assortment $\left(\chi^{2}(1)=\right.$ $1.03, p>.3)$, suggesting that the justification manipulation played a greater role when the choice set called for greater reliance on justifications.

\section{Discussion}

The results of experiment 5 underscore our suggestion that variety influences option choice through greater reliance on accessible justifications; manipulating the ease of justifying indulgences moderated the effect of assortment size on option choice. Consistent with our previous studies, when pleasurable options were harder to justify (i.e., when a manipulation suggested that participants expended less effort than their peers), a larger assortment led to increased choice of utilitarian options. In contrast, when participants had a readily accessible "excuse" for rewarding themselves (i.e.,
FIGURE 3

INFLUENCE OF VARIETY AND RELATIVE EFFORT ON OPTION CHOICE (EXPERIMENT 5)

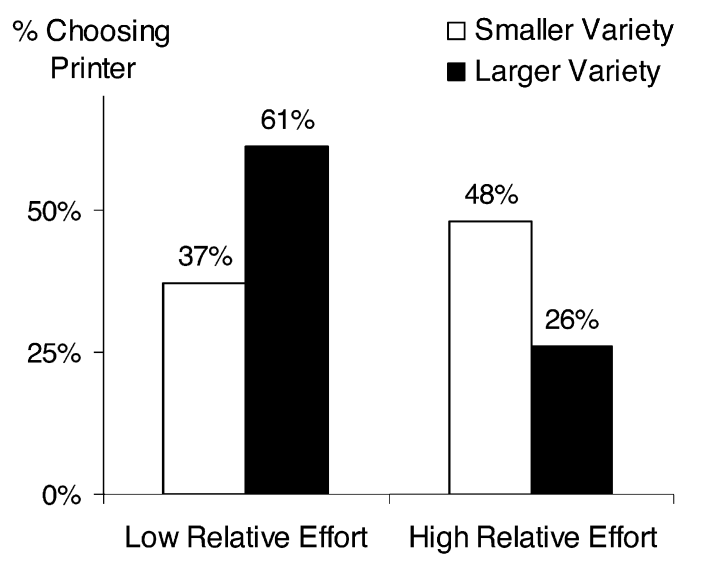

when the manipulation suggested they had exerted more effort than their peers), greater assortment had the opposite effect. For these participants, greater assortment increased the likelihood of choosing pleasurable options.

The results also cast doubt on an alternative account based on a cognitive mode of thought. Such an account has difficulty explaining why the results would be moderated by a justification-based manipulation. Further, a cognitive mode account would suggest that increased assortment should always lead to increased choice of utilitarian options and thus is less useful in explaining why participants in the high relative-effort condition select more hedonic options when choosing from a larger set.

\section{GENERAL DISCUSSION}

This article examines how assortment size influences option choice. Prior research has investigated how too much choice can reduce choice likelihood. In contrast, the present research demonstrates that the number of options consumers are faced with can affect not only whether they choose but also what they choose. Choosing from larger assortments tends to increase choice difficulty and, consequently, can cause consumers to rely more on accessible justifications when making their choice. As a result, we argue that choosing from a larger assortment should lead consumers to select options that are easier to justify.

Five experiments support our perspective. First, they demonstrate that when faced with larger choice sets, people tend to select more virtuous options. They selected reduced fat over regular ice cream (experiment 1A), fruit over cookies (experiment 1B), and utilitarian over hedonic consumer products (experiments $2-5$ ).

Second, the studies demonstrate how choice difficulty and option justifiability drive these effects. Choice difficulty mediated the effect of assortment size on option choice (ex- 
periment 3). Increasing the number of options increased choice difficulty, which, in turn, made people more likely to select options that were easier to justify. Further, the effects were moderated by accessible justifications (experiments 4 and 5). Supporting our framework, the effect found in the first three experiments was reversed when participants had an accessible justification for choosing indulgences. Under these conditions, larger assortments led people to choose hedonic options. Thus, assortment size influences option choice through increased difficulty, but the type of option people will choose will depend on accessible justifications.

The findings also cast doubt on a number of alternative explanations for our results. Although one could argue that the attractiveness of the items in the larger and smaller assortments differed, this cannot explain why assortment would influence choice even when the same options were labeled differently (experiment 4) or why manipulating relative effort or licensing would reverse the results (experiments 4 and 5). An account based on activated cognitive mind-set also has trouble explaining this moderation and, further, does not suggest why increased assortment size might sometimes lead to increased choice of hedonic options (e.g., in the high relative-effort condition in experiment 5). Alternatively, one could argue that increasing the number of options impairs one's ability to think vividly about any single option, thus hurting the attractiveness of hedonic options in particular (which, arguably, depends more on the ability to imagine the consumption experience). Again, however, this explanation has difficulty explaining the moderation observed in experiments 4 and 5. Assortment size should have the same effect on option vividness regardless of relative effort or licensing.

An important boundary condition for these findings is the extent to which larger assortments actually increase choice difficulty. If choosing from larger assortments is not more difficult (e.g., when one option dominates or when consumers have well-defined preferences), then larger assortments should be less likely to influence the type of options consumers choose. It is also possible that choice difficulty can be greater when the number of options is smaller. For example, increasing the choice set from two to three or more options can give rise to context effects that, in some cases, may facilitate easier and more confident decision making (cf. Dhar and Simonson 2003; Yoon and Simonson 2008).

\section{Assortment, Choice Difficulty, and Justification}

While recent work has focused on difficulty and regret as drivers of choice deferral (Iyengar and Lepper 2000), our findings take this insight a step further by linking it to earlier work on justification (Shafir et al. 1993). Most choice-overload studies examined situations where little justification exists for choosing one option versus another. Few people can likely come up with a strong reason for choosing milk chocolate praline over fudge delight ice cream, assuming that the two are equally tempting. Part of the reason these difficult situations may be demotivating, then, is the lack of accessible reasons or justifications to simplify choice.
In situations in which accessible reasons exist, however, choosing from enlarged assortments may be less likely to lead to deferral. Indeed, research suggests that ideal point availability plays an important role in moderating the influence of assortment on consumer preferences (Chernev 2003b). Having a clear idea of what you want provides an obvious reason for selecting certain options, but making any reason accessible, even those that are less related to utility maximization, may help consumers deal with enlarged assortments. Even seemingly irrelevant information (e.g., stating that the previous consumer chose this option) could provide consumers with an accessible reason that may facilitate choice.

\section{Extensions and Practical Implications}

Our theoretical framework leads to a number of broader predictions that can be tested in future research. Research on choice overload suggests that enlarged assortments may lead consumers to be less satisfied with the chosen option, in part because of increased regret. The present research, however, suggests that assortment size may also influence satisfaction with the chosen option by influencing the way that option is evaluated. Increased set size should lead consumers to rely more on justifications for choice; consequently, when they do make a choice, their satisfaction with the chosen option should depend a lot more on how it relates to the available justifications. For example, participants who chose a more utilitarian option from a larger set might actually be more (or less) satisfied with their choice. Similarly, although the increased assortment led many participants to choose more utilitarian options, some participants still selected more hedonic alternatives. As a result of increased reliance on reasons for choice, however, these participants may actually have been less satisfied with their chosen alternative than if they had selected it from a smaller set. Overall, then, the increased justification induced by assortment size should influence not only option choice but also satisfaction with the chosen option.

This research has focused on the role of assortment size in option choice, but other factors that influence choice difficulty may also have similar effects on decision making. One example is attributes. Trading off between more attributes can sometimes increase decision difficulty and may induce greater reliance on justifications for choice. Preliminary evidence indicates that presenting consumers with an enlarged list of attributes can influence choice between utilitarian and hedoic options (Sela and Berger 2009), although the exact mechanism and moderating factors underlying these processes may differ slightly.

Similarly, although we focused on choices between vice and virtue or hedonic and utilitarian options, future research might examine how such justification-based processes influence choice in other important domains. For example, how might a recruiter choosing among job candidates be influenced by the number of applications, their lengths, and the degree of similarity between the individual résumés? To the extent that these factors are associated with greater 
choice difficulty, they are likely to bias choice outcome in favor of choices that are easier to justify. This could potentially lead the recruiter to select participants of particular races, genders, or background characteristics.

Finally, our findings have important managerial and policy implications. For example, manufacturers of healthy snacks would be better off pursuing venues with larger selections. Similarly, an award-winning (but nonentertaining) movie might be better off shown in a 21 -screen multiplex theater rather than a small two-screen theater when rivaling shoot-'em-up action flicks. From a policy perspective, while recent assortment research has illustrated how too much choice can impair social welfare (see Botti and Iyengar [2006] for a review), our studies suggest that assortment can also have positive welfare effects by driving consumers to make more virtuous choices. Although choosing from a larger menu may be demotivating, our findings suggest that when consumers do choose, the option they select is likely to be healthier. This unanticipated benefit of assortment can potentially be used to improve consumer welfare-but with caution. Giving consumers more options should increase their reliance on justifications for choice, but this will only improve their welfare in cases in which those reasons point them to better options. Whether the overall combination of these factors has positive or negative welfare implications remains to be seen.

\section{APPENDIX \\ EXPERIMENT 4}

These laptops are built for fun. They feature high-end graphics cards, top of the line speakers, and extra music and video software.

These laptops are built for work. They are lightweight, have extended battery life, high-end security, and extra business and presentation software.

Acer Aspire 3690 Toshiba Qosimo Lenovo ThinkPad T60 HP Pavilion 6245 Compaq Evo N400c Fujitsu Lifebook P7630

*Extra options in the larger assortment condition are underlined.

\section{REFERENCES}

Baron, Reuben M. and David A. Kenny (1986), "The ModeratorMediator Variable Distinction in Social Psychological Research: Conceptual, Strategic and Statistical Considerations," Journal of Personality and Social Psychology, 51 (6), 1173-82.

Baumol, William J. and Edward A. Ide (1956), "Variety in Retailing," Management Science, 3 (1), 93-101.

Bazerman, Max H., Ann E. Tenbrunsel, and Kimberly Wade-Benzoni (1998), "Negotiating with Yourself and Losing: Making Decisions with Competing Internal Preferences," Academy of Management Review, 23 (2), 225-41.

Berger, Jonah, Michaela Draganska, and Itamar Simonson (2007), "The Influence of Product Variety on Brand Perception and Choice," Marketing Science, 26 (4), 460-72.

Berlyne, Daniel E. (1960), Conflict, Arousal, and Curiosity, New York: McGraw-Hill.

Böhm, Gisela and Hans-Rüdiger Pfister (1996), "Instrumental or Emotional Evaluations: What Determines Preferences," Acta Psychologica, 93 (1-3), 135-48.

Botti, Simona and Sheena S. Iyengar (2006), "The Dark Side of Choice: When Choice Impairs Social Welfare," Journal of Public Policy and Marketing, 25 (1), 24-38.

Chernev, Alexander (2003a), "Product Assortment and Individual Decision Processes," Journal of Personality and Social Psychology, 85 (1), 151-62.

(2003b), "When More Is Less and Less Is More: The Role of Ideal Point Availability and Assortment in Consumer Choice," Journal of Consumer Research, 30 (September), 170-83.
Set A

Set B

These laptops are built for work. They are lightweight, have extended battery life, high-end security, and extra business and presentation software.

These laptops are built for fun. They feature high-end graphics cards, top of the line speakers, and extra music and video software.

Options*

Acer Aspire 4570 Toshiba Satellite P75 Lenovo ThinkPad T45 HP Pavilion 6285c Compaq Presario 725 Fujitsu Lifebook P7230

Dhar, Ravi (1997), "Consumer Preference for a No-Choice Option Source," Journal of Consumer Research, 24 (September), 215-31.

Dhar, Ravi and Itamar Simonson (1999), "Making Complementary Choices in Consumption Episodes: Highlighting versus Balancing," Journal of Marketing Research, 36 (February), 2944.

(2003), "The Effect of Forced Choice on Choice," Journal of Marketing Research, 40 (May), 146-60.

Hsee, Christopher K. (1995), "Elastic Justification: How Tempting but Task-Irrelevant Factors Influence Decisions," Organizational Behavior and Human Decision Process, 62 (3), 330-37.

Hsee, Christopher K. and Yuval Rottenstreich (2004), "Music, Pandas, and Muggers: On the Affective Psychology of Value," Journal of Experimental Psychology, 133 (1), 23-30.

Iyengar, Sheena S., Gur Huberman, and Wei Jiang (2004), "How Much Choice Is Too Much? Contributions to 401(k) Retirement Plans," in Pension Design and Structure: New Lessons from Behavioral Finance, ed. Olivia S. Mitchell and Stephen P. Utkus, Oxford: Oxford University Press, 83-95.

Iyengar, Sheena S. and Mark R. Lepper (2000), "When Choice Is Demotivating: Can One Desire Too Much of a Good Thing?" Journal of Personality and Social Psychology, 79 (6), 995-1006.

Kahn, Barbara E. and Rebecca Ratner (2005), "Variety for the Sake of Variety? Diversification Motives in Consumer Choice," in Inside Consumption: Frontiers of Research on Consumer Motives, Goals, and Desires, ed. Srinivasan Ratneshwar and David Glen Mick, London: Routledge, 102-21. 
Khan, Uzma and Ravi Dhar (2006), "Licensing Effect in Consumer Choice," Journal of Marketing Research, 43 (May), 259-66.

Kivetz, Ran (1999), "Advances in Research on Mental Accounting and Reason-Based Choice," Marketing Letters, 10 (3), 249-66.

Kivetz, Ran and Anat Keinan (2006), "Repenting Hyperopia: An Analysis of Self-Control Regrets," Journal of Consumer Research, 33 (September), 273-82.

Kivetz, Ran and Itamar Simonson (2002a), "Earning the Right to Indulge: Effort as a Determinant of Customer Preferences toward Frequency Program Rewards," Journal of Marketing Research, 39 (May), 155-70.

(2002b), "Self-Control for the Righteous: Toward a Theory of Precommitment to Indulgence," Journal of Consumer Research, 29 (September), 199-217.

Kivetz, Ran and Yuhuang Zheng (2006), "Determinants of Justification and Self-Control," Journal of Experimental Psychology: General, 135 (4), 572-87.

Lancaster, Kelvin J. (1990), "The Economics of Product Variety: A Survey," Marketing Science, 9 (3), 189-206.

Langer, Ellen J. and Judith Rodin (1976), "The Effects of Choice and Enhanced Personal Responsibility for the Aged: A Field Experiment in an Institutional Setting," Journal of Personality and Social Psychology, 34 (2), 191-98.

Lascu, Dana N. (1991), "Consumer Guilt: Examining the Potential of a New Marketing Construct," in Advances in Consumer Research, Vol. 18, ed. Rebecca Holman and Michael Solomon, Ann Arbor, MI: Association for Consumer Research, 290-95.

O'Curry, Suzanne and Michal Strahilevitz (2001), "Probability and Mode of Acquisition Effects on Choices between Hedonic and Utilitarian Options," Marketing Letters, 12 (1), 37-49.

Prelec, Drazen and George Loewenstein (1998), "The Red and the Black: Mental Accounting of Savings and Debt," Marketing Science, 17 (1), 4-28.

Schwartz, Barry (2004), The Paradox of Choice: Why More Is Less, New York: Ecco.
Sela, Aner and Jonah Berger (2009), "The Dual Effects of Product Attributes on Choice: Creating Difficulty or Providing Excuses," working paper, Marketing Department, Stanford Graduate School of Business, Stanford, CA.

Shafir, Eldar, Itamar Simonson, and Amos Tversky (1993), "Reason-Based Choice," Cognition, 49 (1-2), 11-36.

Simonson, Itamar (1989), "Choice Based on Reasons: The Case of Attraction and Compromise Effects Source," Journal of Consumer Research, 16 (September), 158-74.

(1992), "The Influence of Anticipating Regret and Responsibility on Purchase Decisions," Journal of Consumer Research, 19 (June), 105-18.

Simonson, Itamar and Stephen M. Nowlis (2000), "The Role of Explanations and Need for Uniqueness in Consumer Decision Making: Unconventional Choices Based on Reasons," Journal of Consumer Research, 27 (June), 49-68.

Small, Deborah, George Loewenstein, and Paul Slovic (2007), "Sympathy and Callousness: The Impact of Deliberative Thought on Donations to Identifiable and Statistical Victims," Organizational Behavior and Human Decision Processes, 102 (2), 143-53.

Sobel, Michael E. (1982), "Asymptotic Confidence Intervals for Indirect Effects in Structural Equation Models," Sociological Methodology, 13, 290-312.

Strahilevitz, Michal and John G. Myers (1998), "Donations to Charity as Purchase Incentives: How Well They Work May Depend on What You Are Trying to Sell," Journal of Consumer Research, 24 (March), 434-46.

Tversky, Amos and Eldar Shafir (1992), "Choice under Conflict: The Dynamics of Deferred Decision," Psychological Science, 3 (6), 358-61.

Weber, Max (1958), The Protestant Ethic and the Spirit of Capitalism, New York: Scribner.

Yoon, Song-Oh and Itamar Simonson (2008), "Choice Set Configuration as a Determinant of Preference Attribution and Strength," Journal of Consumer Research, 35 (August), 324-36. 